\title{
AN EMPIRICAL VERIFICATION OF THE COMMUNITY OF INQUIRY FRAMEWORK
}

\author{
J. B. Arbaugh \\ University of Wisconsin Oshkosh
}

\section{INTRODUCTION}

Despite the explosion of empirical research on online learning effectiveness over the last decade, development and acceptance of theoretical frameworks unique to the online learning environment are still relatively lacking. While there are several emerging models [1, 2, 3], one that has attracted some of the most attention is the Community of Inquiry (CoI) framework developed by Garrison, Anderson and Archer [4]. A search of Google Scholar shows that Garrison and colleagues' article describing the framework has been cited in other works at least 161 times as of September 2006, making it by far the most cited article in The Internet and Higher Education to date. However, while individual components of the CoI framework have been examined empirically $[5,6,7,8]$, studies that simultaneously study all three components of the framework are extremely limited, and those that do exist tend to be conducted by those who developed the framework [9].

The purpose of this paper is to report on the results of a study that examines whether the CoI dimensions of social, teaching and cognitive presence distinctively exist in e-learning environments. The rest of the paper is organized as follows. First, I will briefly review recent studies on the dimensions of this framework: social, cognitive, and teaching presence. Second, I discuss the development of the sample of MBA students in online courses over a two-year period at a Midwestern U.S. university and the items used to measure the CoI dimensions. Next, I will describe the results of an exploratory factor analysis, including an interpretation of the emerging factors. Finally, I will discuss how these findings relate to conclusions presented in Garrison's review of recent research related to the CoI [10] and present some possible directions for future research.

\section{THE COMMUNITY OF INQUIRY FRAMEWORK}

Garrison and colleagues developed the CoI framework to investigate how features of written language used in computer conferencing activities promote critical/higher-order thinking [4]. They contend that higher-order learning experiences are best conducted as a community of inquiry composed of teachers and learners requiring both the demonstration of critical thinking and the engagement of "real" persons to be successful. The framework assumes that effective online learning is a function of the interaction of three elements: social presence, cognitive presence, and teaching presence. In the following section, I will describe and review some recent literature on each of these types of presence.

\section{A. Social Presence}

Social presence in online learning has been described as the ability of learners to project themselves socially and emotionally, thereby representing themselves as "real people" in mediated communication $[11,12]$. Of the three types of presence included in the CoI framework, social presence has been the most extensively studied, both in online and face-to-face course settings $[6,11,13,14]$. 
Presently there is an emerging debate on whether social presence has a causal or correlational relationship with online course outcomes $[6,8]$. Recent research on social presence in online learning also has focused on its role in facilitating cognitive development and critical thinking. To date, this research suggests that while social presence alone will not ensure the development of critical discourse in online learning, it is extremely difficult for such discourse to develop without a foundation of social presence [15]. A recent study on the effects of interpersonality in online learning [16] suggest that increased sociability of course participants leads to increased interaction, therefore implying that social presence is necessary for the development of cognitive presence. Anagnostopoulos and colleagues' [17] identification of a concept they called intersubjective modality that provides further support for this premise. According to these authors, intersubjective modality in the online environment occurs when a participant explicitly refers to another participant's statement when developing their own post, thereby both connecting themselves to the other participant and laying the foundation for higher level inquiry. Other recent studies supporting the "social presence as foundation for cognitive presence" perspective include those by Molinari [18] and Celani and Collins [19].

\section{B. Cognitive Presence}

Garrison, Anderson, and Archer [20] described cognitive presence as the extent to which learners are able to construct and confirm meaning through sustained reflection and discourse. Rooted in Dewey's [21] construction of practical inquiry and the critical thinking it seeks as an outcome, cognitive presence has long been considered to be a distinguishing characteristic of higher education [22, 23]. Garrison and colleagues [20] argue that cognitive presence in online learning is developed as the result of a four phase process. These phases are: (1) a triggering event, where some issue or problem is identified for further inquiry; (2) exploration, where students explore the issue both individually and corporately through critical reflection and discourse; (3) integration, where learners construct meaning from the ideas developed during exploration-Garrison and colleagues [20] proposed that this phase typically requires enhanced teaching presence to probe and diagnose ideas so that learners will move to higher level thinking in developing their ideas; and (4) resolution, where learners apply the newly gained knowledge to educational contexts or workplace settings.

Of the three types of presence in the CoI framework, cognitive presence likely is the one most challenging to develop in online courses [19, 15, 24]. While participant interaction certainly is foundational for developing cognitive presence, it appears that critical thinking skill might be enhanced via a variety of online course formats [24, 25, 26]. One possible approach for increasing collective cognitive engagement within online groups is the SQUAD approach developed by Oriogun and colleagues [27] The SQUAD approach encourages participants to make posts in one of five categories: suggestion, question, unclassified, answer, and/or delivery. Conversely, Moore and Mara [24] found that developing discussions using an argumentative approach appears to adversely affect both the quantity and quality of participant interaction. A possible explanation for why multiple formats may be effective for enhancing cognitive presence may be that group composition is more important than discussion format. Lee and Lee [28] recently found that student groups with a variety of personalities may be more effective in developing metacognitive interaction than do groups comprised of only extroverted or introverted learners.

Emerging research suggests a complementary relationship between teaching presence and cognitive presence. While social presence lays the groundwork for higher-level discourse, the structure, organization, and leadership associated with teaching presence creates the environment where cognitive presence can be developed. Garrison and Cleveland-Innes [15] found that course design, structure and leadership significantly impact the extent to which learners engage course content in a deep and meaningful manner. These findings suggest that the role of instructors in cultivating cognitive presence is 
An Empirical Verification of the Community of Inquiry Framework

significant, both in terms of how they structure the course content and participant interactions.

\section{Teaching Presence}

Teaching presence is described by Garrison and colleagues [4] as the design, facilitation, and direction of cognitive social processes for the purpose of realizing personally meaningful and educationally worthwhile learning outcomes. They conceptualized teaching presence as having three components: (1) instructional design and organization; (2) facilitating discourse (originally called "building understanding”); and (3) direct instruction.

While teaching presence is conceptualized as being equally important as social presence and cognitive presence in the CoI framework, it generally hasn't received research attention until the adoption of the internet as a mainstream instructional medium [4]. As a result, while the number of studies of teaching presence has markedly increased over the last five years, they have tended to be exploratory in nature. These studies have relied primarily either on transcript analysis studies of a limited number of courses [29, 30,31] or basic statistical techniques such as frequency distributions and correlational analyses to determine the extent to which teaching presence exists in online classrooms [7].

The most recent research on teaching presence has focused on two areas: (1) empirical verification of the dimensionality of the construct; and (2) the extent to which teaching presence relies upon the actual presence of the instructor in the online course. In a recent study of the SUNY Learning Network [32], Shea found that items developed to measure the three dimensions of teaching presence yielded a two factor solution he interpreted as "Instructional Design and Organization" and "Directed Facilitation," thereby merging the instructor behavior dimensions of the construct. Conversely, in a study of MBA students, Arbaugh and Hwang [5] found support for the three-dimensional teaching construct. Therefore, since the institutions from which Shea [32] developed his sample were mostly community colleges, it is possible that the differences in student and instructor populations may explain the divergence in these findings.

The fact that both of these studies found that Instructional Design and Organization was a distinct construct is particularly relevant to research on the importance of the teacher's role in teaching presence. While Garrison and Cleveland-Innes [15] found strong support for the instructor's role in creating teaching presence, other recent research suggests the possibility that a well-designed course may limit or even negate the need for the instructor. For example, Anagnostopoulos and colleagues [17] found that design features of a graduate-level course in literature education actually allowed students to navigate around the presence of the instructor, prompting the instructor to adopt a more democratized participation style in asynchronous discussions in order to get students to interact with her. However, they also found that the instructor was able to play a more traditional role in synchronous discussions. These findings were also supported in LaPointe and Gunawardena's study [33] finding positive relationships between course design, direct instruction and perceived teaching style, but a negative relationship between facilitation and teaching style in a convenience sample comprised largely of community college students. However, other recent studies have found strong support for the importance of instructor presence (informational, social, and content-wise) early in the online course for helping both building community and easing students into online communication [34, 35].

Based on the results of this brief review, it appears that the much of the recent empirical research on these types of presence has relied upon relatively small sample sizes (typically less than 50) in limited numbers of class sections within the same discipline (often one course, rarely more than five) and for the most part is qualitative in nature. As a result, the generalizability of these findings is somewhat questionable. 
Therefore, research on the CoI would greatly benefit from more quantitatively-oriented studies that examine multiple courses and disciplines. Hence, this study appears to be particularly timely.

\section{RESEARCH METHODOLOGY}

\section{A. Sample and Data Collection}

The sample for this study came from 55 of the 56 online courses conducted in the MBA program of a Mid-Western U. S. university over six semesters from February 2004 through January 2006. These classes covered topics including organizational behavior/theory, international business, business strategy, human resource management, project management, operations management, information systems, finance, accounting, and professional development. This university was in the midst of a transition between course management software systems during the period of the study. Therefore, six of the courses in the first two semesters of the study were conducted using the Blackboard software platform, while the remaining courses were conducted on a relatively new platform called Desire To Learn (D2L). Both course management systems have synchronous and asynchronous interaction capability. The classes were distance learning classes with students taught primarily through asynchronous web-based interactions, and forty of the class sections had an on-site orientation meeting. Class sizes ranged from 7 to 49 .

Data collection was completed in a two-step process. In the first step, students were emailed a survey during the final week of the course regarding their perceptions of the learning environment, course management system, instructor behaviors, the knowledge they acquired, and their satisfaction with the internet as the course delivery medium. The second step was conducted 7-10 days after the electronic survey was sent. In this step, students who had not responded to the electronic survey were mailed a paper copy of the original survey. 667 students provided useable responses, resulting in a response rate of $55.1 \%$ (667 of 1,211). All respondents were graduate business students. The mean student age was 32.6 $(\mathrm{SD}=6.90)$, and $57 \%$ of the respondents were male.

\section{B. Measures}

While the dimensions of the CoI framework have been examined via content analysis [20, 29, 31], the survey-based measures that were adopted in this study allow for the use of a larger and wider sample in a relatively efficient way, thereby increasing the generalizability of the findings. The scales for teaching presence (Course Design and Organization-6 items; Facilitating Discourse-7 items; and Direct Instruction - 5 items) were developed by Shea and colleagues in their study of teaching presence in the SUNY Learning Network [7]. Eight items measuring social presence were adapted from measures used in Richardson and Swan's study [6], which in turn were developed from Gunawardena and Zittle's and Short and colleagues' conceptualizations [11,12] of the construct. While some survey-based measures of cognitive presence are now available [9], these were not available at the beginning of this study. Therefore, four items were developed based on Garrison and colleagues' conceptualization [20] of cognitive presence. These items place particular focus on the final three (exploration, integration, and resolution) phases of construct since the first phase, the "triggering event", often is expressed as part of teaching presence [15]. All survey items were anchored on a 7-point scale ranging from "Strongly Agree" to "Strongly Disagree."

\section{RESULTS}

While survey-based measures for social presence are well established in previous research, valid and reliable measures of teaching presence can be best described as a work in progress [5, 32]. Furthermore, 
measures of cognitive presence are extremely limited. With the exception of Garrison and colleagues' study [9], there are no known studies that simultaneously examine these three constructs. Therefore, for these reasons as well as the relative newness of the CoI framework and the use of new measures for cognitive presence, the data were analyzed using exploratory factor analysis via principal components analysis using SAS's Factor procedure with varimax rotation [36, 37], Cattell's Scree test [38] and Kaiser's eigenvalues [39] greater than 1 criteria each identified four factors, which collectively accounted for $68.75 \%$ of the variance in the survey items. The four factors and their loadings from each of the survey items are presented in Table 1 . As Table 1 shows, all factors have reliability alphas of .86 or higher, which is well above the recommended .7 for exploratory research [40]. A description of each of the factors is provided in the following paragraphs. Based on guidelines developed by Gorsuch [41] and Stevens [37], only survey items that loaded at .40 or higher were used to interpret the factors. A description of each of the factors is provided below.

Table 1. Factor Loadings for CoI Survey Items (n=667)

\begin{tabular}{|l|c|c|c|c|}
\hline & $\begin{array}{l}\text { Factor 1: } \\
\text { Teaching } \\
\text { Presence }\end{array}$ & $\begin{array}{l}\text { Factor 2: } \\
\text { Social } \\
\text { Presence }\end{array}$ & $\begin{array}{l}\text { Factor 3: } \\
\text { Cognitive } \\
\text { Presence }\end{array}$ & $\begin{array}{l}\text { Factor 4: } \\
\text { Course } \\
\text { Design } \\
\text { Organization }\end{array}$ \\
\hline Chronbach's Alpha & .97 & .88 & .90 & .89 \\
\hline $\begin{array}{l}\text { P1 The instructor clearly communicated } \\
\text { important course goals }\end{array}$ & .52 & .18 & .22 & .65 \\
\hline $\begin{array}{l}\text { P2 The instructor clearly communicated } \\
\text { important course topics }\end{array}$ & .52 & .20 & .20 & .59 \\
\hline $\begin{array}{l}\text { P3 The instructor provided clear } \\
\text { instructions on how to participate in course } \\
\text { learning activities }\end{array}$ & .49 & .17 & .22 & .65 \\
\hline $\begin{array}{l}\text { P4 The instructor clearly communicated } \\
\text { important due dates/time frames for } \\
\text { learning activities }\end{array}$ & .24 & .18 & .10 & .72 \\
\hline $\begin{array}{l}\text { P5 The instructor helped me take } \\
\text { advantage of the online environment to } \\
\text { assist my learning }\end{array}$ & .75 & .25 & .19 & .26 \\
\hline $\begin{array}{l}\text { P6 The instructor helped students } \\
\text { understand and practice acceptable } \\
\text { behaviors in online learning environments }\end{array}$ & .73 & .22 & .16 & .22 \\
\hline $\begin{array}{l}\text { P7 The instructor was helpful in } \\
\text { identifying areas of agreement and } \\
\text { disagreement on course topics that helped } \\
\text { me to learn }\end{array}$ & .80 & .20 & .21 & .22 \\
\hline $\begin{array}{l}\text { P8 Other learners were helpful in } \\
\text { identifying areas of agreement and } \\
\text { disagreement that helped me learn }\end{array}$ & .52 & .44 & .22 \\
\hline $\begin{array}{l}\text { P9 The instructor was helpful in guiding } \\
\text { the class towards agreement/understanding } \\
\text { about course topics that helped me to learn }\end{array}$ & .82 & .16 & .26 \\
\hline $\begin{array}{l}\text { P11 The instructor acknowledged student } \\
\text { participation in the course }\end{array}$ & .75 & .16 & \\
\hline
\end{tabular}




\begin{tabular}{|c|c|c|c|c|}
\hline $\begin{array}{l}\text { P13 The instructor encouraged students to } \\
\text { explore concepts in the course }\end{array}$ & .78 & .20 & .17 & .21 \\
\hline $\begin{array}{l}\text { P15 The instructor helped to keep students } \\
\text { engaged and participating in productive } \\
\text { dialogue }\end{array}$ & .88 & .15 & .12 & .10 \\
\hline $\begin{array}{l}\text { P17 The instructor helped keep the } \\
\text { participants on task in a way that helped } \\
\text { me to learn }\end{array}$ & .85 & .18 & .18 & .16 \\
\hline $\begin{array}{l}\text { P19 The quality of interaction with my } \\
\text { online instructor was very high in this } \\
\text { course }\end{array}$ & .83 & .16 & .23 & .21 \\
\hline $\begin{array}{l}\text { P21 The instructor presented content or } \\
\text { questions that helped me to learn }\end{array}$ & .72 & .23 & .29 & .29 \\
\hline $\begin{array}{l}\text { P23 The instructor helped to focus } \\
\text { discussion on relevant issues in a way that } \\
\text { helped me to learn }\end{array}$ & .76 & .23 & .26 & .23 \\
\hline $\begin{array}{l}\text { P25 The instructor provided explanatory } \\
\text { feedback that helped me to learn }\end{array}$ & .77 & .14 & .25 & .20 \\
\hline $\begin{array}{l}\text { P27 The instructor helped me to revise my } \\
\text { thinking }\end{array}$ & .74 & .16 & .35 & .08 \\
\hline $\begin{array}{l}\text { P28 Other participants helped me to revise } \\
\text { my thinking }\end{array}$ & .43 & .40 & .36 & -.11 \\
\hline $\begin{array}{l}\text { P29 The instructor provided useful } \\
\text { information from a variety of sources that } \\
\text { helped me to learn }\end{array}$ & .61 & .16 & .41 & .28 \\
\hline $\begin{array}{l}\text { P32 Online courses are an excellent } \\
\text { medium for social interaction }\end{array}$ & .17 & .64 & .28 & -.08 \\
\hline $\begin{array}{l}\text { P33 I felt comfortable conversing through } \\
\text { the online medium }\end{array}$ & .08 & .81 & .07 & .15 \\
\hline $\begin{array}{l}\text { P34 Participant introductions enabled me } \\
\text { to form a sense of online community }\end{array}$ & .35 & .56 & .26 & -.12 \\
\hline $\begin{array}{l}\text { P35 I felt comfortable participating in the } \\
\text { course discussions }\end{array}$ & .11 & .76 & .08 & .30 \\
\hline $\begin{array}{l}\text { P36 The instructor created a feeling of } \\
\text { online community }\end{array}$ & .70 & .36 & .22 & .05 \\
\hline $\begin{array}{l}\text { P38 I felt comfortable interacting with } \\
\text { other course participants }\end{array}$ & .15 & .79 & .13 & .28 \\
\hline $\begin{array}{l}\text { P39 I felt that my point of view was } \\
\text { acknowledged by other course participants }\end{array}$ & .19 & .71 & .16 & .13 \\
\hline $\begin{array}{l}\text { P40 I was able to form distinct impressions } \\
\text { of some course participants }\end{array}$ & .28 & .55 & .17 & .16 \\
\hline $\begin{array}{l}\text { P41 I have been able to apply knowledge } \\
\text { created in this course to subsequent class } \\
\text { assignments }\end{array}$ & .30 & .19 & .72 & .18 \\
\hline P42 I have been able to apply the & .34 & .20 & .81 & .08 \\
\hline
\end{tabular}




\begin{tabular}{|l|c|c|c|c|}
\hline $\begin{array}{l}\text { knowledge created in this course to my } \\
\text { work or other non-class related activities }\end{array}$ & & & & \\
\hline $\begin{array}{l}\text { P43 I can describe ways to test and apply } \\
\text { the knowledge created in this course }\end{array}$ & .29 & .28 & .76 & .21 \\
\hline $\begin{array}{l}\text { P44 I will be able to apply the knowledge } \\
\text { created in this course to future work or } \\
\text { other non-class related activities }\end{array}$ & .29 & .24 & .79 & .19 \\
\hline
\end{tabular}

Note: Loadings .40 or greater noted in bold.

\section{A. Factor 1: Teaching Presence}

Considering that 20 of the 32 items used in the survey were originally used to measure teaching presence, it is not surprising that this factor had the most items with significant loadings. Nineteen of the 20 items used to measure teaching presence loaded significantly upon this factor. One item previously used to measure the course design and organization characteristic of this construct, "The instructor clearly communicated important due dates/time frames for learning activities (P4)," did not load significantly onto this factor. One of the items previously used to measure social presence "The instructor created a feeling of online community (P36)," loaded significantly on this factor. Considering the importance of instructor behaviors in the roles of facilitating discourse and direct instruction [32], the fact that this item would load onto the teaching presence rather than the social presence factor is not surprising.

\section{B. Factor 2: Social Presence}

Seven of the eight items historically used to measure social presence loaded at .55 or higher on this variable. The other item used to measure social presence, "The instructor created a feeling of online community (P36)," had a moderate .36 loading on this factor. Two items previously developed to measure the role that other learners have in creating teaching presence [4, 7], "Other learners were helpful in identifying areas of agreement and disagreement that helped me learn (P8)" and "Other participants helped me to revise my thinking (P28)," had moderate loadings upon this factor (.44 and .40 respectively).

\section{Factor 3: Cognitive Presence}

Each of the four items developed for this study to measure cognitive presence loaded onto this factor at .72 or higher. The combination of these loadings and a reliability coefficient of .90 suggest preliminary support for the construct validity of these items [40]. Three items used to previously used to measure direct instruction, "The instructor helped me to revise my thinking (P27)", "Other participants helped me to revise my thinking (P28)", and "The instructor provided useful information from a variety of sources that helped me to learn (P29),” also loaded at least moderately onto this factor (.35, .36, and .41 respectively). Those loadings may reflect that these items capture some of the aspects of the practical inquiry model, particularly the exploration and integration phases [20].

\section{Factor 4: Course Design and Organization}

Four of the six items originally developed to measure the course design and organization dimension of teaching presence $[4,7]$ loaded at .59 or higher on this factor. Three of these four items also loaded at 49 or higher on the teaching presence factor, indicating that this could be an extraneous factor. However, the fact that these four items have high reliability (alpha $=.89$ ) and that no other item in the survey loaded higher than .30 on this factor suggest at least the possibility that course design and organization is a 
distinct construct from teaching presence. This finding could have significant implications given the results of recent research on the teaching presence construct [10], and these potential implications will be addressed in the next section of this paper.

\section{DISCUSSION}

The results of this study should provide some encouragement to those researchers interested in testing the generalizability of the CoI framework. The results indicate that these survey items are highly reliable, somewhat empirically distinct measures for each of the three elements. However, in some ways these results may generate as many questions as answers for future research. In this section of the paper, we will interpret the findings of the study in light of issues recently raised by Garrison [10] regarding research on the CoI framework and propose additional directions for future CoI research.

In a recent review of social presence research, Garrison [10] notes that most of the initial research on this element of the CoI examined it independently of the other two types of presence. Therefore, the fact that this study examines social presence in concert with teaching and cognitive presence represents an advance in research on the CoI framework. However, given the emerging discussion of social presence in elearning environments, there may be some limitations to these measures of social presence. While empirically distinct and reliable, the items measuring social presence in this study do not capture the shift from personal to purposeful relationships that Garrison [10] calls for. Garrison's review raises several questions related to the role of collaborative processes and the interaction of social and cognitive presence. Perhaps future research in this area can examine the literature on trust and performance in global virtual teams for useful insights into the nature of the interaction between these two elements [42, 43].

By addressing the later stages of the critical inquiry process, the items developed to measure cognitive presence for this study may address Garrison's call [10] for a "step forward" in research on this element. There are at least two possible explanations for this finding that merit further research. First, while some approaches to online learning research criticize using data collected after the learning experience is completed [44]; such an approach may be advantageous for studying cognitive presence because it allows for the possibility that learners might need time to complete the higher-order phases of the critical inquiry process. Therefore, techniques such as transcript analysis [10] may not completely capture the cognitive inquiry process and should be supplemented with some sort of data collection at the end of the course. Second, these findings suggest the possibility that characteristics of degree program and level of study might influence the occurrence of cognitive presence in online learning. While the nature of assignments and discussion questions provided in e-learning environments can encourage progression to higher stages of cognitive inquiry [45, 46], learner contexts also may be important in promoting inquiry. Online courses conducted in an MBA program targeted at students that have full-time professional positions may draw participants that can readily identify experiences to which they can apply higher level cognitive processes, where this may not be the case in learning environments such as community college or undergraduate level general education courses.

While this measure of cognitive presence may help advance survey-based research on the CoI, there are two methodological concerns that can be addressed by future researchers. First, while the items address higher-order phases of the cognitive inquiry process, they may not adequately capture earlier stages, particularly the "triggering event". Future research should consider integrating the items from this study with Garrison and colleagues' measures for cognitive presence [9]. Another benefit of such an approach is that it would improve the balance between the numbers of items used to measure the three CoI elements. Using 4-6 items to measure cognitive presence when up to 20 items are used to measure teaching 
An Empirical Verification of the Community of Inquiry Framework

presence likely will result in unbalanced coverage of the elements of the framework.

In his review of research on the CoI framework, Garrison [10] noted that one of the primary questions regarding the study of teaching presence is whether it is a two- or three-dimensional construct. Recent studies by Shea [31] and Arbaugh and Hwang [5] make compelling arguments for the importance of this question. While a possible explanation for the divergence of findings of these studies could be degree level of the samples (Shea examined primarily undergraduates while Arbaugh and Hwang studied graduate students exclusively), unfortunately, the results of this study of a sample of MBA students if anything further muddles this issue. On one hand, items designed to measure each of the three conceptualized dimensions loaded strongly on one factor. On the other hand, several of the items designed to measure course design and organization loaded strongly on a separate factor, suggesting the possibility that "teaching presence" could be two factors: course design and directed facilitation [31].

A possible explanation for this these types of findings may be the way that teaching presence is being operationalized. In spite of initial conceptualization of the possibility that teaching presence could be created by either an instructor or fellow learners [4], these recent studies operationalizations of teaching presence have focused on instructor behavior. So therefore, what we may actually be measuring is "teacher presence." Given recent research results indicating the importance of instructors in virtual learning environments $[47,48,49,50]$ this may merely reflect the reality of the online environment rather than a flawed conceptualization. These initial studies might suggest a modified CoI model based on sequence of activities. Since course design and organization occurs prior to the beginning of the course, it could be a distinct variable followed by the intermingled elements of social presence, cognitive presence, and teacher presence. However, another possible explanation for the finding of a fourth factor may be due to the analytical technique. Garrison and colleagues [9] have argued that empirical studies of the CoI components using factor analysis should use oblique rotations due to the highly interdependent nature of the three types of presence. While testing newly developed measures for cognitive presence and combining measures previously not used together for the other types of presence were the motivations for using varimax rotation for this study, one consequence of that approach may have been a confounding of the constructs.

Regardless of conclusions reached regarding the dimensionality and distinctiveness of the components of this construct, a practical matter that needs to be addressed by future researchers is the need to determine how teaching presence can be measured more efficiently relative to the other elements of the CoI framework. Both Shea's and Arbaugh and Hwang's studies [31, 5] used at least seventeen items to measure teaching presence. While using such a large number of items to help precisely define a relatively new construct is understandable and desirable, a more efficient measure of teaching presence likely will help increase survey response rates for future studies of the CoI framework. Again, future researchers should examine the items used in these studies and those used by Garrison and colleagues [9] to determine the optimal combination of items for construct validity, reliability, and efficiency. While Garrison and colleagues [9] developed measures for social, cognitive, and teaching presence that had factor loadings that may address some of the concerns about the interaction of social and cognitive presence, that study's relatively small sample size $(n=65)$ forces conclusions drawn from it to be somewhat tentative. Table 2 compares the sample characteristics of this study with that of Shea's (2006) and Garrison and colleagues (2004). 
Table 2. Contextual Factors in Recent CoI Studies

\begin{tabular}{|l|c|c|c|}
\hline & $\begin{array}{c}\text { Garrison, Cleveland- } \\
\text { Innes, \& Fung (2004) }\end{array}$ & Shea (2006) & Present Study \\
\hline Sample Ssize & 65 & 2314 & 667 \\
\hline Student Level & Graduate - Education & Associate \& Bachelor’s & Graduate - Business \\
\hline Courses Surveyed & 6 & Up to 581 & 55 \\
\hline Disciplines & Education & Numerous & Business \\
\hline Institutions Sampled & 1 & 32 & 1 \\
\hline
\end{tabular}

One suggestion for future researchers may be to combine items from the two surveys to determine the best measures of these elements, particularly for cognitive presence.

In addition to the issues raised by Garrison [10], the findings presented here suggest new opportunities for future researchers. The items used in this study should allow for more robust testing of how the CoI elements coexist with, and/or moderate the effects of other variables associated with online learning outcomes. While the elements of the CoI framework are seen as overlapping in nature [4, 9, 51], Garrison's discussions [10] of the interaction between the types of presence and results of the studies reviewed in this article suggest that studies using moderated regression to determine the extent to which the elements moderate each others' relationship to learning outcomes is much needed. In addition to examining relationships between the elements of the framework, some other variables that researchers should consider studying in concert with the CoI elements include the course or subject matter [50, 52, $53]$, the software used to deliver the course [54, 55, 56], and characteristics of learners and/or instructors $[50,55,57,58,59]$.

\section{CONCLUSION}

This article reported on an empirical verification of the elements of the CoI framework, which found empirically distinct measures of social, cognitive, and teaching presence. The results of the study strongly support Garrison's conclusion [10] that CoI research now needs to move beyond exploratory descriptive studies to the use of both qualitative and quantitative methods. Now that there are some initial tools in place, it is up to future researchers to use and refine these measures to advance CoI research.

\section{REFERENCES}

1. Alavi, M. and D. E. Leidner. Research commentary: Technology-mediated learning-A call for greater depth and breadth of research. Information Systems Research 12(1): 1-10, 2001.

2. Benbunan-Fich, R., S. R. Hiltz and L. Harasim. The online interaction learning model: An integrated theoretical framework for learning networks. In: S. R. Hiltz and R. Goldman (Eds.), Learning Together Online: Research on Asynchronous Learning Networks, 19-37. Mahwah, NJ: Lawrence Erlbaum Publishers, 2005.

3. Rungtusanatham, M., L. M. Ellram, S. P. Siferd and S. Salik. Toward a typology of business education in the internet age. Decision Sciences Journal of Innovative Education 2(2): 101-120, 2004.

4. Garrison, D. R., T. Anderson and W. Archer. Critical inquiry in a text-based environment: Computer conferencing in higher education. The Internet and Higher Education 2: 87-105, 2000.

5. Arbaugh, J. B. and A. Hwang. Does "teaching presence" exist in online MBA courses? The Internet and Higher Education 9: 9-21, 2006. A preliminary analysis of the data used in Arbaugh and 
An Empirical Verification of the Community of Inquiry Framework

Hwang's study examined items that measured student perceptions of course design and both the instructor and other learners roles in facilitation of discourse and direct instruction. A factor analysis showed that these items loaded on two factors: (1) Instructor behaviors and (2) Student behaviors.

6. Richardson, J. C. and K. Swan. Examining social presence in online courses in relation to students' perceived learning and satisfaction. Journal of Asynchronous Learning Networks 7(1): 2003. http://www.sloan-c.org/publications/jaln/v7n1/v7n1_richardson.asp.

7. Shea, P. J., E. E. Fredericksen, A. M. Pickett and W. E. Pelz. A preliminary investigation of "teaching presence" in the SUNY learning network. In: J. Bourne and Janet C. Moore (Eds.), Elements of Quality Online Education: Into the Mainstream, Vol. 4, 279-312. Needham, MA: SloanC, 2003.

8. Wise, A., J. Chang, T. Duffy and R. del Valle. The effects of teacher social presence on student satisfaction, engagement, and learning. Journal of Educational Computing Research 31: 247-271, 2004.

9. Garrison, D. R., M. Cleveland-Innes and T. Fung. Student role adjustment in online communities of inquiry: Model and instrument validation. Journal of Asynchronous Learning Networks 8(2): 2004. http://www.sloan-c.org/publications/jaln/v8n2/v8n2_garrison.asp.

10. Garrison, D. R. Online community of inquiry review: Social, cognitive, and teaching presence issues. Paper presented at the Sloan-C Summer workshop, Baltimore, MD, 2006.

11. Gunawardena, C. and F. Zittle. Social presence as a predictor of satisfaction within a computer mediated conferencing environment. American Journal of Distance Education 11(3): 8-26, 1997.

12. Short, J., E. Williams and B. Christie. The Social Psychology of Telecommunication. London: Wiley, 1976.

13. Rourke, L., T. Anderson, D. R. Garrison and W. Archer. Methodological Issues in the Content Analysis of Computer Conference Transcripts. International Journal of Artificial Intelligence in Education 12(1): 8-22, 2001.

14. Walther, J. Interpersonal effects in computer mediated interaction: A relational perspective. Communication Research 19(1): 52-90, 1992.

15. Garrison, D. R. and M. Cleveland-Innes. Facilitating cognitive presence in online learning: Interaction is not enough. American Journal of Distance Education 19(3): 133-148, 2005.

16. Beuchot, A. and M. Bullen. Interaction and interpersonality in online discussion forums. Distance Education 26(1): 67-87, 2005.

17. Anagnostopoulos, D., K. G. Basmadjian and R. S. McCrory. The decentered teacher and the construction of social space in the virtual classroom. Teachers College Record 107: 1699-1729, 2005.

18. Molinari, D. L. The role of social comments in problem-solving groups in an online class. American Journal of Distance Education 18(2): 89-101, 2004.

19. Celani, M. A. A. and H. Collins. Critical thinking in reflective sessions and in online interactions. AILA Review 18: 41-57, 2005.

20. Garrison, D. R., T. Anderson and W. Archer. Critical thinking, cognitive presence, and computer conferencing in distance education. American Journal of Distance Education 15(1): 7-23, 2001.

21. Dewey, J. How We Think. Boston: Heath, 1933.

22. Dauer, F. W. Critical Thinking: An Introduction to Reasoning. Oxford: Oxford University Press, 1989.

23. Dewey, J. My pedagogic creed. In: Dewey, J. (Ed.), Dewey on Education, New York: Teachers College, Columbia University, 19-32, 1959.

24. Moore, J. L. and R. M. Marra. A comparative analysis of online discussion participation protocols. Journal of Research on Technology in Education 38: 191-212, 2005.

25. Duphorne, P. L. and C. N. Gunawardena. The effect of three computer conferencing designs on critical thinking skills of nursing students. American Journal of Distance Education 19(1): 37-50, 2005. 
26. Schrire, S. Interaction and Cognition in Asynchronous Computer Conferencing. Instructional Science: An International Journal of Learning and Cognition 32: 475-502, 2004.

27. Oriogun P. K. Towards understanding online learning levels of engagement using the SQUAD approach. Australian Journal of Educational Technology 19(3): 371-388, 2003. http://www.ascilite.org.au/ajet/ajet19/ajet19.html.

28. Lee, J-M. and Y. Lee. Personality types and learners' interaction in web-based threaded discussion. Quarterly Review of Distance Education 7(1): 83-94, 2006.

29. Anderson, T., L. Rourke, D. R. Garrison and W. Archer. Assessing teaching presence in a computer conferencing context. Journal of Asynchronous Learning Networks 5(2), 2001. http://www.sloan-c.org/publications/jaln/v5n2/v5n2_anderson.asp.

30. Fahy, P. J. Use of linguistic qualifiers and intensifiers in a computer conference. American Journal of Distance Education 16(1): 5-22, 2002.

31. Jefferies, P., F. Grodzinsky and J. Griffin. Advantages and problems in using information communication technologies to support the teaching of a multi-institutional computer ethics course. Journal of Educational Media 28(2-3): 191-202, 2003.

32. Shea, P. J. A study of students' sense of learning community in online learning environments. Journal of Asynchronous Learning Networks 10(1): $2006 . \quad$ http://www.sloanc.org/publications/jaln/v10n1/v10n1_4shea.asp.

33. LaPointe, D. K. and C. N. Gunawardena. Developing, testing, and refining a model to understand the relationship between peer interaction and learning outcomes in computer-mediated conferencing. Distance Education 25(1): 83-106, 2004.

34. Conrad, D. L. Engagement, excitement, anxiety, and fear: Learners' experiences of starting an online course. American Journal of Distance Education 16(4): 205-226, 2002.

35. Stein, D. S., C. E. Wanstreet, J. Calvin, C. Overtoom and J. E. Wheaton. Bridging the transactional distance gap in online learning environments. American Journal of Distance Education 19(2): 105-118, 2005.

36. Hair, J. F. Jr., R. E. Anderson, R. L. Tatham and W. C. Black. Multivariate Data Analysis ( ${ }^{\text {rd }}$ Ed.). New York: MacMillan, 1992.

37. Stevens, J. P. Applied Multivariate Statistics for the Social Sciences (4 ${ }^{\text {th }}$ Ed.). Mahwah, NJ: Erlbaum, 2002.

38. Cattell, R. B. The scree test for the number of factors. Multivariate Behavioral Research 1: 245-276, 1966.

39. Kaiser, H. F. The application of electronic computers to factor analysis. Educational and Psychological Measurement 20: 141-151, 1960.

40. Nunnally, J. C. Psychometric Theory ( $2^{\text {nd }}$ Ed.). New York: McGraw-Hill, 1978.

41. Gorsuch, R. L. Factor Analysis ( ${ }^{\text {nd }}$ Ed.). Hillsdale, NJ: Erlbaum, 1983.

42. Jarvenpaa, S. L. and D. E. Leidner. Communication and trust in global virtual teams. Organization Science 10: 791-815, 1999.

43. Jarvenpaa. S. L., T. R. Shaw and D. S. Staples. Toward contextualized theories of trust: The role of trust in global virtual teams. Information Systems Research 15: 250-267, 2004.

44. Hodgson, V. and P. Watland. Researching networked management learning. Management Learning 35(2): 99-116, 2004.

45. Arnold, N. and L. Ducate. Future foreign language teachers' social and cognitive collaboration in an online environment. Language Learning \& Technology 10(1): 42-66, 2006. Retrieved June 23, 2006 from http://lit.msu.edu/vol10num1/pdf/arnoldducate.pdf.

46. Meyer, K. A. Evaluating online discussions: Four different frames of analysis. Journal of Asynchronous Learning Networks 8(2): 101-114, 2004.

47. Benbunan-Fich, R. and J. B. Arbaugh. Separating the effects of knowledge construction and group collaboration in web-based courses. Information \& Management 43: 778-793, 2006.

48. Brower, H. H. On emulating classroom discussion in a distance-delivered OBHR course: Creating an on-line community. Academy of Management Learning and Education 2(1): 22-36, 2003. 
49. Coppola, N. W., S. R. Hiltz and N. G. Rotter. Becoming a virtual professor: Pedagogical roles and asynchronous learning networks. Journal of Management Information Systems 18(4): 169-189, 2002.

50. Drago, W., J. Peltier and D. Sorensen. Course content or instructor - Which is more important in online teaching? Management Research News 25(6/7): 69-83, 2002.

51. Garrison, D. R., T. Anderson and W. Archer. A theory of critical inquiry in online distance education. In: M. G. Moore \& W. G. Anderson (Eds.), Handbook of Distance Education, 113-127. Mahwah, NJ: Lawrence Erlbaum Associates, 2003.

52. Arbaugh, J. B. How much does "subject matter" matter? A study of disciplinary effects in on-line MBA courses. Academy of Management Learning \& Education 4: 57-73, 2005.

53. Wallace, R. M. Online Learning in Higher Education: A review of research on interactions among teachers and students. Education, Communication, and Information 3(2): 241-280, 2002.

54. Arbaugh, J. B. Is there an optimal design for on-line MBA courses? Academy of Management Learning \& Education 4: 135-149, 2005.

55. Finlay, W. K., C. K. Desment and L. K. Evans. Is it the technology or is it the teacher? A comparison of online and traditional English composition classes. Journal of Educational Computing Research 31: 163-180, 2004.

56. Martins, L. L. and F. W. Kellermanns. A model of business school students' acceptance of a webbased course management system. Academy of Management Learning and Education 3: 7-26, 2004.

57. Hiltz, S. R. and P. Shea. The student in the online classroom. In: S. R. Hiltz \& R. Goldman (Eds.) Learning Together Online: Research on Asynchronous Learning Networks, 145-168. Mahwah, NJ: Lawrence Erlbaum Publishers, 2005.

58. Schniederjans, M. J. and E. B. Kim. Relationship of student undergraduate achievement and personality characteristics in a total web-based environment: An empirical study. Decision Sciences Journal of Innovative Education 3: 205-221, 2005.

59. Dziuban, C., P. Shea and J. B. Arbaugh. Faculty roles and satisfaction in asynchronous learning networks. In: S. R. Hiltz and R. Goldman (Eds.), Learning Together Online: Research on Asynchronous Learning Networks, 169-190. Mahwah, NJ: Lawrence Erlbaum Publishers, 2005. 